\title{
ANALYSIS FOR WATER MITIGATION OPTIONS USING MCDA: A CASE STUDY IN THE GALAPAGOS ISLANDS
}

\author{
MARIA F. REYES ${ }^{1}$, ALEKSANDAR PETRICIC ${ }^{1}$, NEMANJA TRIFUNOVIC ${ }^{1}$, \\ SAROJ SHARMA ${ }^{1} \&$ MARIA D. KENNEDY ${ }^{1,2}$ \\ ${ }^{1}$ Envrionmental Engineering and Water Technology Department, UNESCO-IHE (Institute for Water Education). \\ ${ }^{2}$ Faculty of Civil Engineering and Geosciences, Delft University of Technology, Delft.
}

\begin{abstract}
Lately, due to overutilization of scarce natural resources such as water, tourist islands have been severely threatened. This is also the case in Santa Cruz Island, the main inhabited island of the Galápagos Archipelago. Therefore, a Multi-Criteria Decision Analysis (MCDA) was carried out with the aim of mitigating the future water crisis. The proposed solutions were evaluated in terms of environmental, technical, economic and social criteria. The results indicate that the 'best' alternative for municipality representatives is the option including desalination. However, for the other two groups of stakeholders, the chosen option was the one that combined all the proposed alternatives (greywater recycling, specific demand reduction and rainwater harvesting), except desalination. Conclusions show that for most stakeholders the environment is the most important criteria.

Keywords: Galápagos, intervention strategies, multi-criteria decision analysis, tropical islands, water supply indicators
\end{abstract}

\section{INTRODUCTION}

Tourism is a major source of income and employment in most small tropical islands [1]. Despite the fact that many islands worldwide have limited water resources, the expansion of tourism over the last 40 years has not stopped [2], affecting natural resources, especially water. As a consequence of tourism and local population growth, water demand has increased dramatically, causing several deficiencies on water supply and sewer services, which is directly related to the provision of facilities and services required by tourists [3-5].

The lack of freshwater resources in Galápagos has been a challenge to residents and visitors since these islands were first discovered. Since 1980, the resident population has quadrupled from 5,500 inhabitants to 26,000 in 2010, while the number of visitors has increased from 17,500 to 200,000 in the same period of time. This increase in the number of residents and visitors has created major challenges for the conveyance of water supply. Local authorities have been unable to keep up with rapid population growth and development, in terms of upgrading and maintaining the water supply infrastructure and service, especially in Puerto Ayora, the main hub of tourism. This is primarily due to: weak and unstable governance, lack of eco-friendly policies, and unplanned urbanization, among others $[6,7]$.

Based on the study carried out by [8], several population growth rates were proposed, which became the basis for the modelling of future coverage of water demand with supply made by [9]. The later study considered also several alternatives as intervention strategies for solving the future water deficit in Puerto Ayora. Nevertheless, the environmental vulnerability of Galápagos calls for an integrated and more complex analysis, considering several disciplines. According to [10], any issue involving the decision-making process of natural resources assessment, applies for MCDA. This methodology allows the proposed alternatives to be reviewed based on the perspectives of relevant stakeholders. Therefore the alternatives need to be properly weighted in order to evaluate as accurate as possible the potential solutions, and finally decide which is the most feasible and/or sustainable one considering the different conditions. 
In this paper, several intervention strategies proposed to solve the future water crisis, are evaluated with the MCDA approach. These strategies were assessed under the feedback of seven groups of stakeholders. Also, an equal weight session was included, in order to analyse equal distribution of the chosen criteria for the analysis.

\section{MULTI-CRITERIA DECISION ANALYSIS}

The MCDA is an integrated and complete assessment of multiple suggested alternatives, with a set of tools for any decision-making process. This type of analyses comprises applied mathematical algorithms which evaluate a set of measures with different values and factors. The evaluation is usually carried out on problems with conflicting goals, high uncertainty, different forms of data and information, multiple interests and perspectives, and complex and/or evolving biophysical and socio-economic systems [11]. The ultimate goal of this methodology is to define the most feasible and sustainable solution of a certain issue at a low cost and considering all preferences of the participants [12].

Even though this type of analyses has been considered as subjective, the use of MCDA method has increased rapidly since the 1990s, especially with environment-related researches. This has been mainly due to the high complexity of projects, and an increased level of public and stakeholder participation [13]. According to [14], the use of MCDA methodologies provides a reliable method, which allows to rank different proposed alternatives in the presence of numerous objectives and constraints. Moreover, one of the advantages of the MCDA is the capacity to involve several stakeholders' opinions and perspectives. This results in a more thorough understanding of the points of view held by the involved parties [15].

Figure 1 shows the steps that were followed to carry the MCDA of the proposed alternatives for ensuring the future water demand coverage in Puerto Ayora [16].

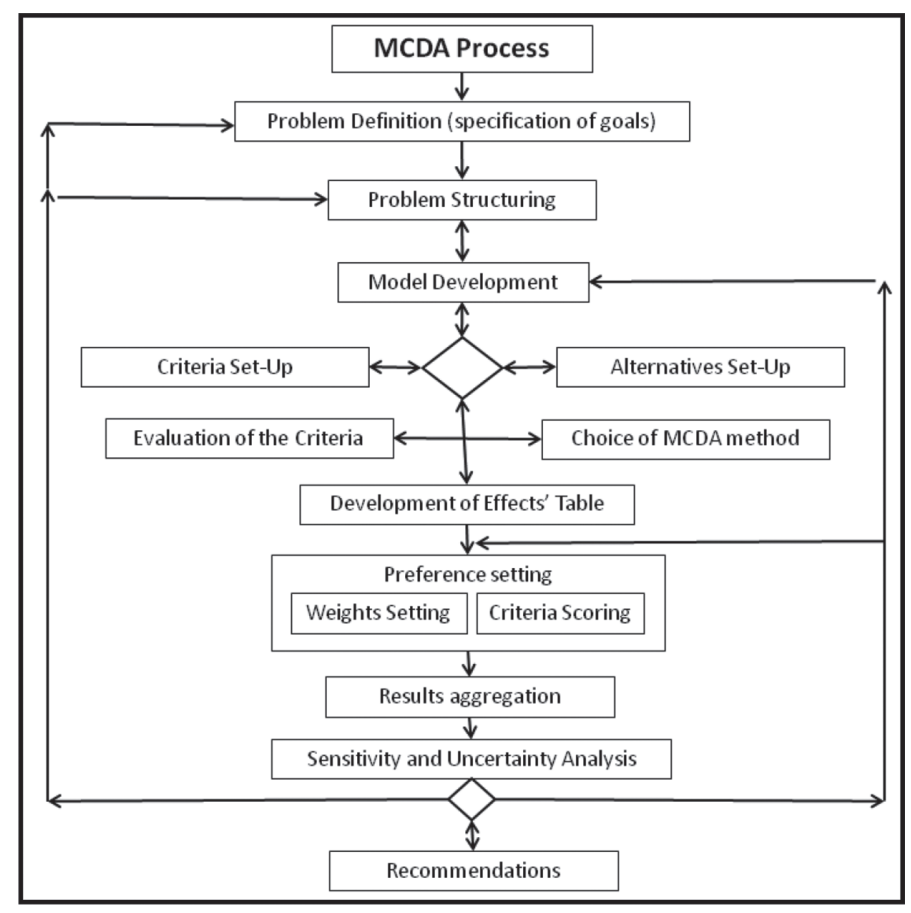

Figure 1: Schematic of the MCDA procedure. 


\section{RESEARCH METHODOLOGY}

First, the problem was defined as the water supply deficit in the town of Puerto Ayora in the year 2044. In order to solve this issue, the study made by [17], developed with the help of the WaterMet ${ }^{2}$ model [18] forecasted the water demand coverage over a 30-year planning horizon, proposing five intervention strategies. The results for the end of the forecast period (2045) were the basis for the input data for the MCDA. This analysis was carried out using the DEFINITE software [19], since it is a highly used program for complex-environmental case studies. It was developed to help improve the decision-making process with clear methodologies. Table 1 describes each selected intervention strategy.

Afterwards, four main criteria were selected for this analysis: (1) environmental, (2) technical, (3) economic and (4) social. Each of these was further described with different indicators, which allowed to evaluate the impact and performance of each strategy under the previously defined criteria. The indicators assigned are as follows:

- ENVIRONMENTAL CRITERIA: Land use, discharge of wastewater, seawater intrusion, energy consumption, chemical use, impact on endemic species, impact on marine/ land ecosystems.

- TECHNICAL CRITERIA: Improvement on hours of service, coverage of demand with supply, water losses, robustness of the water supply system, O\&M of the water supply system, alternative water sources contribution to overall balance, compatibility with the existing system.

- ECONOMIC CRITERIA: Capital cost, O\&M cost, non-revenue water income generation, water demand management income generation, employment generation, increase in water tariffs, increase in tourist capacity.

- SOCIAL CRITERIA: Social acceptability, willingness to pay, transparency on project implementation process, water quality improvement, annual infection and other waterrelated diseases risk, compatibility with current legislations.

For this analysis, the DEFINITE software was selected, since it can be used on a wide variety of problems, regarding different disciplines. It is a software developed in order to improve the quality of decision, by a methodical procedure which leads experts through a number of interactive assessment sessions. It uses an optimization approach to integrate all information

Table 1: Intervention strategies selected and modelled with WaterMet ${ }^{2}$ software.

\section{Intervention strategy Description}

GALAPAGOS 1

GALAPAGOS 2

GALAPAGOS 3

GALAPAGOS 4

GALAPAGOS 5
Leakage Reduction + Water Meter Installation

Leakage Reduction + Desalination Plant Installation + Water

Meter Installation

Leakage Reduction + Rainwater Harvesting + Greywater Recycling

Water Meter Installation + Rainwater Harvesting + Greywater Recycling

Leakage Reduction + Water Meter Installation + Rainwater

Harvesting + Greywater Recycling + Water Demand

Reduction

Source: [17] 
provided by the selected involved stakeholders to a full set of value functions leading to a scientific-based alternative [19].

In the next step, each indicator defined for every criterion was scored. This scoring is expressed in an 'effects table', which refers to the assessment of the performance of each strategy against all the pre-defined indicators in a qualitative or quantitative way. The missing information was taken from the literature, such as potential waste quantities from the different selected strategies, as well as laws and regulations used locally. Another information was also taken from interviews with local experts, including the information for indicators for the social criteria and the technical one. Every indicator was scored using different types of scales/units, either qualitative or quantitative.

Afterwards, the scores assigned to each indicator were standardized. Since the values in the effects table were not in the same units, they were standardized with values between 0 and 1 . For this, different methods were used: the maximum method, the goal standardization, the convex function and the yes/no standardization.

Following the standardization, every criterion was allocated with a weight. For this, a questionnaire was distributed to selected stakeholders, clustered into three different categories: municipality representatives, laundries and local community as shown in Figure 1.

\section{RESULTS AND DISCUSSION}

The MCDA was conducted in a total of four sessions. The first one illustrates the ranking result of the analysis using equal weights of all criteria. The other three analyses provide ranking results according to different weights allocation provided by the stakeholders. The ranking results are illustrated in Figure 3.

As observed in the previous figures, the best overall ranking result is achieved by alternative Galápagos 5. It is ranked on the first place in three different sessions. However, it takes the second place only in the municipality representatives' session. The Galapagos 5 option is the most consistent alternative of all, since the weight score ranges from 0.56 to 0.63 , taking always the first or the second place. Even thought the Galápagos 2 alternative is the only one to provide full demand coverage at the end of the project horizon, it only takes the first place in one session (municipality representatives), and then second, but taking the fourth place in

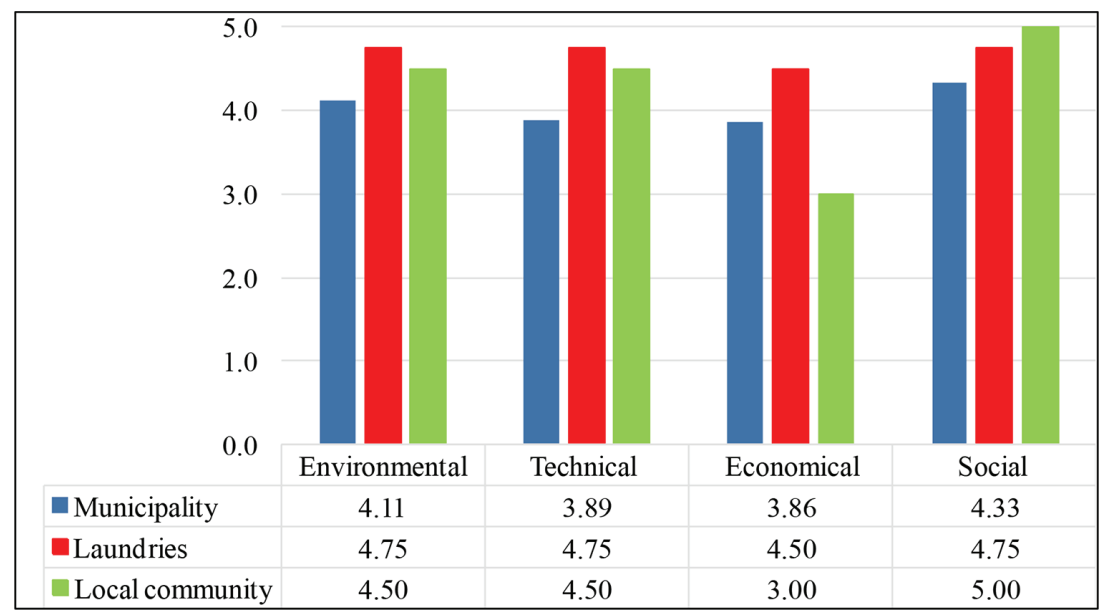

Figure 2: Ranking preferences of various stakeholders' groups in Puerto Ayora. 

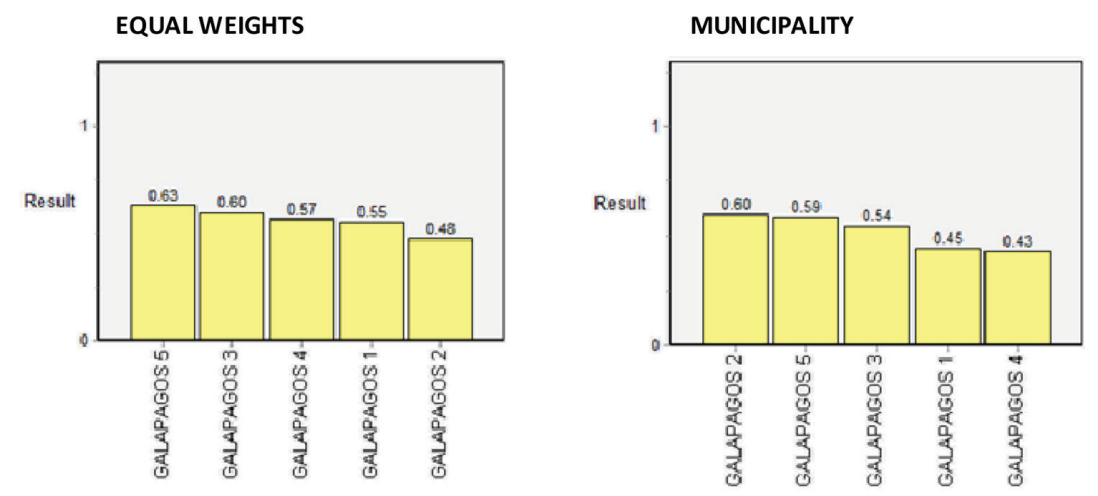

(a)

LAUNDRIES

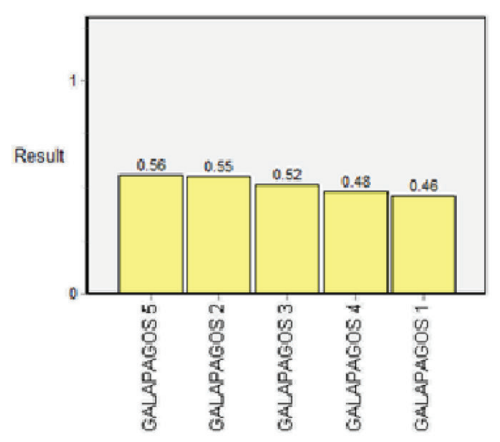

LOCAL COMMUNITY

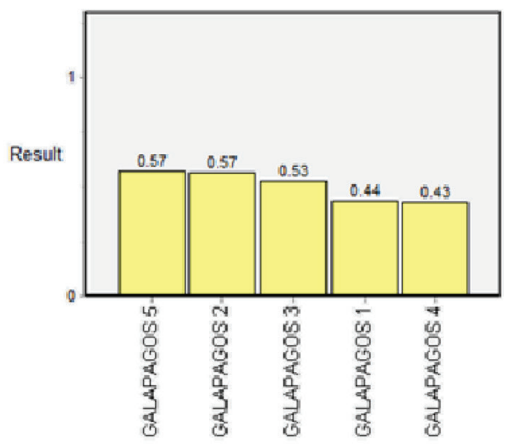

(b)

Figure 3: Ranked results from different stakeholders' perspectives (a) equal weights and municipality representatives, and (b) laundries and local community.

the equal weights' session. This is a consequence of the high costs and environmental threats attributed to this option.

As observed, the dispute is mainly between Galapagos 5 and Galapagos 2 alternatives. This indicates that whenever the environment is given more preference, Galapagos 5 tends to take the lead, while Galapagos 2 takes its place if technical criteria are given preference.

The staked bar charts (Fig. 4) provide more detailed information regarding the contribution level of each criterion on the overall score of the different MCDA sessions. The Galápagos 2 alternative, due to the large contribution from technical and social criteria, is the preferred option for the municipality representatives. This is due to the high scores obtained for the indicators under the social and technical criteria, since it is the alternative that can cover the total demand amount, and improving significantly the water quality.

For the rest of the three sessions, which give priority to alternative Galápagos 5, have assigned a higher weight to the environmental criteria, followed by the technical, and economic criteria respectively. This alternative scores reasonably well in all of the defined criteria, which results in the most consistent distribution of its rank across all of the sessions.

The summary of the ranking results from all MCDA sessions under this analysis is provided in Figure 5. The score allocation, together with the rank positions for each alternative gives a clear picture on resulting values and their frequencies. 
LEGEND:

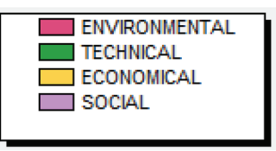

EQUAL WEIGHTS

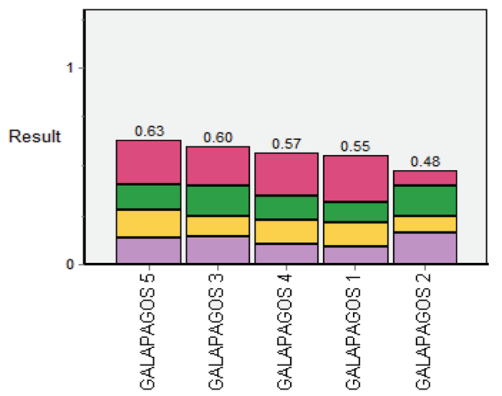

(a)

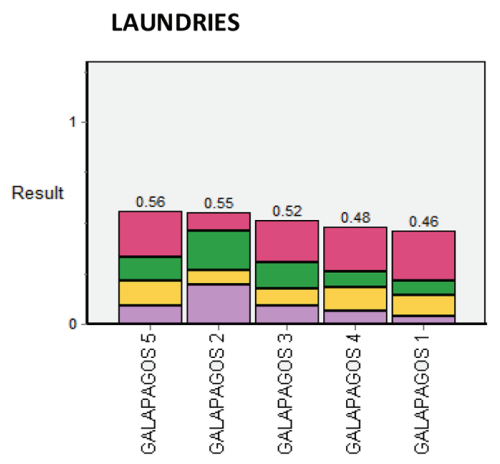

MUNICIPALITY

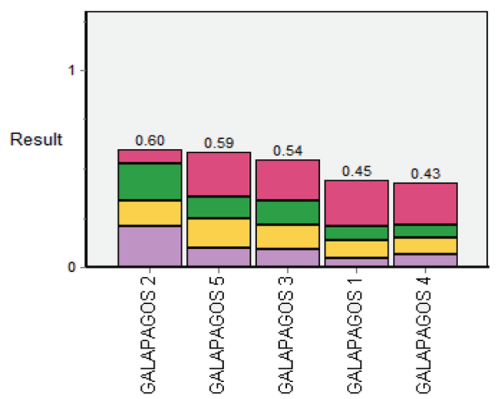

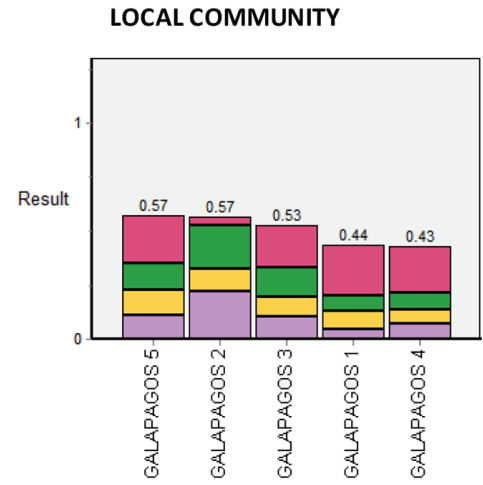

(b)

Figure 4: Stacked bar charts explaining the contribution of each criterion to the total score for each session for (a) equal weights and municipality representatives, and (b) laundries and local community.

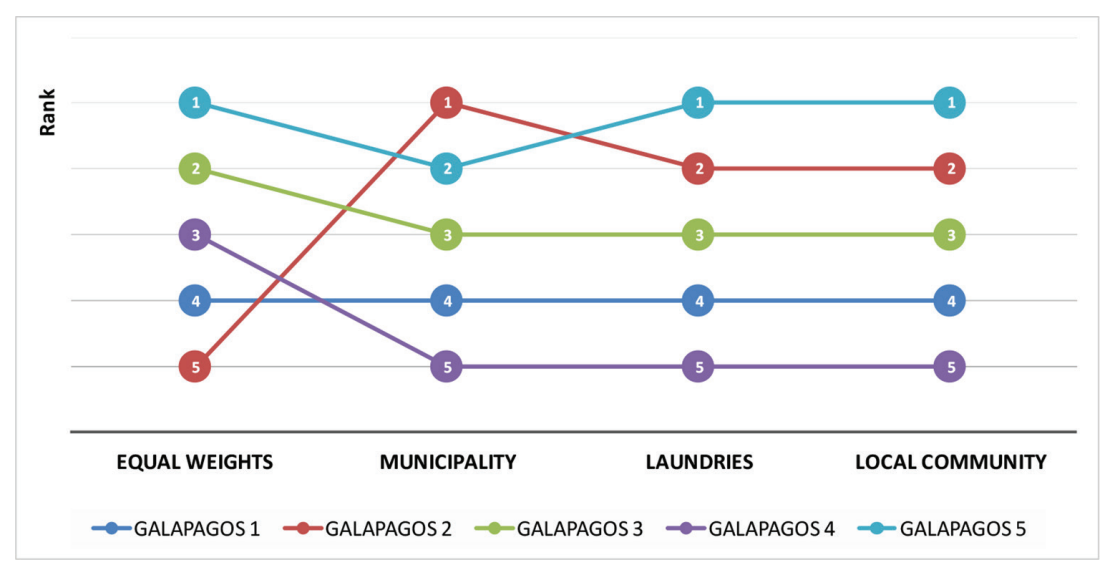

Figure 5: Comparison of MCDA results for Puerto Ayora case study. 
As observed in the previous figure, each alternative tends to have a certain ranking, with variations of one step higher or lower, but not drastic changes in the ranking, except Galapagos 2. This alternative, in the equal sessions, takes the last place, suggesting that the technical criteria do not have a significant influence in the final results, due to the importance given to this ecosystem. Therefore, the environment indicators weight more than the technical ones. The most stable alternative is Galapagos 1, which takes the fourth place in all of the sessions. The variation of the rankings, suggests that a sensitivity analysis will help further in the explanation of how the results may vary with variations in weights and input values.

\section{CONCLUSIONS}

The MCDA methodology has proven to be a suitable decision support tool, which may provide a complete analysis regarding future water supply and demand options. However, the indicators, as well as their original values and ranges, have been proven to be case dependant and case sensitive. In this study, different sets of measures for improving the water supply system of Puerto Ayora were analyzed with four main groups of criteria.

As results showed, the Galapagos 2 and Galapagos 5 alternatives were ranked on the first positions by different stakeholder groups. Galapagos 2, which includes desalination, was preferred by municipality representatives only. On the other hand, Galapagos 5 was preferred by the other three groups of stakeholders, which included all of the options, except desalination. These differences in the results can be attributed to the technical and environmental preferences given. Nevertheless, despite these obvious advantages given by Galapagos 2, due to the higher costs and negative environmental impacts identified, it can easily be replaced by Galapagos 5 in most of the sessions, and other stakeholders seem to prefer less coverage of water demand if it preserves better the ecosystem. This also suggests that many of local population call for more sustainable options must, which replace desalination, in order to avoid possible harmful environmental threats.

Finally, more studies would be needed to arrive at more accurate values of certain quantitative indicators. These studies include long-term modelling (hydraulic, hydro-geological, physical, demographic and economic impact, etc.). More detailed determination of social criteria is needed as well, in order to come up with proper descriptive values for the qualitative indicators.

\section{REFERENCES}

[1] Tsiourtis, N.X., Water charge, the Cyprus experience. Water valuation and cost recovery mechanisms in the developing countries of the Mediterranean Region. CIHEAM-IAMB, Bari, pp. 91-104, 2002.

[2] Essex, S., Tourism development in Mallorca: is water supply a constraint? Journal of Sustainable Tourism, 12(1), pp. 4-28, 2004.

https://doi.org/10.1080/09669580408667222

[3] Charara, N., Cashman, A., Bonnell, R. \& Gher, R. Water use efficiency in the hotel sector of Barbados. Journal of Sustainable Tourism, 19(2), pp. 231-245, 2010. https://doi.org/10.1080/09669582.2010.502577

[4] Bramwell, B. Maltese responses to tourism. Annals of Tourism Research, 30(3), pp. 581-605, 2003. https://doi.org/10.1016/s0160-7383(03)00023-9 
[5] Gössling, S., Peeters, P, Hall, C., Ceron, J., Dubois, G., Lehmann, L. \& Scott, D., Tourism and water use: supply, demand, and security. An international review. Tourism management, 33(1), pp. 1-15, 2012.

https://doi.org/10.1016/j.tourman.2011.03.015

[6] Reyes, M., Trifunovic, N., Sharma, S. \& Kennedy, M., Data assessment for water demand and supply balance on the island of Santa Cruz (Galápagos Islands). Desalination and Water Treatment, 57(45), pp. 21335-21349, 2015. https://doi.org/10.1080/19443994.2015.1119756

[7] González, J. A., Montes, C, Rodrigues, J. \& Tapia W., Rethinking the Galapagos Islands as a complex social-ecological system: implications for conservation and management. Ecology and Society, 13(2), pp. 13, 2008. https://doi.org/10.5751/es-02557-130213

[8] Mena, C., et al., Determination of social, environmental and economical relations which allow the development based on different processes of modelling, potential scenarios of sustainability of the socio-ecological system of the Galápagos Islands with emphasis on the dynamic of the flux of tourist visitors. Report for the Ministry of Environment. Unpublished, 2014.

[9] Reyes, M., Trifunović, N., Sharma, S. \& Kennedy, M., Water supply and demand forecasting in Puerto Ayora-Santa Cruz. Manuscript presented at the 14th Islands of the World Conference, Lesvos, Greece, May 23-27, 2016.

[10] Linkov, I., Satterstrom, F. Kiker, G., Batchelor, C., Bridges T. \& Ferguson, E., From comparative risk assessment to multi-criteria decision analysis and adaptive management: recent developments and applications. Environment International, 32, pp. 1072-1093, 2006.

https://doi.org/10.1016/j.envint.2006.06.013

[11] Wang, J.J., Jing, Y.Y., Zhang, C.F. \& Zhao, J.H., Review on multi-criteria decision analysis aid in sustainable energy decision-making. Renewable and Sustainable Energy Reviews, 13(9), pp. 2263-2278, 2009. https://doi.org/10.1016/j.rser.2009.06.021

[12] Linkov, I. \& Moberg, E., Multi-criteria decision analysis: Environmental applications and case studies. Boca Raton, CRC Press Taylor and Francis Group, 2012.

[13] Salanguste-Anarna, M., Development of a multi-criteria decision support system for seawater desalination plants, MSc Thesis, UNESCO-IHE, Institute for water education, The Netherlands, 2009.

[14] Polatidis, H., Haralambopoulos, D.A., Munda, G. \& Vreeker, R., Selecting an appropriate multi-criteria decision analysis technique for renewable energy planning. Energy Sources, Part B, 1(2), pp. 181-193, 2006. https://doi.org/10.1080/009083190881607

[15] Kiker, G.A., Bridges, T.S., Varghese, A., Seager, T.P. \& Linkov, I., Application of multicriteria decision analysis in environmental decision making. Integrated Environmental Assessment and Management Journal, 1(2), pp. 95-108, 2005.

https://doi.org/10.1897/ieam_2004a-015.1

[16] Yatsalo, B.I., Didenko, V., Gritsyuk, S. \& Sullivan, T., Decerns: a framework for multi criteria decision analysis. International Journal of Computational Intelligence Systems, 8, pp. 467-489, 2015. https://doi.org/10.1080/18756891.2015.1023586 
[17] Behzadian, K., Kapelan, Z., Venkatesh, G., Brattebø, H. \& Sægrov, S., WaterMet 2: a tool for integrated analysis of sustainability-based performance of urban water systems. Drinking Water Engineering and Science Discussions, 7(1), pp. 1-26, 2014. https://doi.org/10.5194/dwesd-7-1-2014

[18] Reyes, M., Trifunovic, N., Sharma, S., Behzhadian, K., Kapelan, Z. \& Kennedy, M., Mitigation options for future water scarcity: a case study of Santa Cruz Island (Galápagos Archipelago). Under Review In Water Journal, 2017.

[19] Janssen, R. \& Herwijnen, M., DEFINITE for Windows: A system to support decisions on a finite set of alternatives (Software packages and user manual) Institute for environmental studies (IVM). Vrije Universiteit, Amsterdam, 2011. 